\title{
Autism and the Built Environment
}

\author{
Pilar Arnaiz Sánchez ${ }^{1}$, Francisco Segado Vázquez ${ }^{2}$ \\ and Laureano Albaladejo Serrano ${ }^{2}$ \\ ${ }^{1}$ Universidad de Murcia \\ ${ }^{2}$ Universidad Politécnica de Cartagena \\ Spain
}

\section{Introduction}

Heidegger (2001) ended his essay entitled "Building, dwelling, thinking", with an exhortation to "build out of dwelling, and think for the sake of dwelling". Many definitions have been given for Architecture throughout history, but it is (or at least it should be) clear that its centre, its aim, its main objective, is the act of dwelling. This is the reason why Norberg-Schultz (1980) affirms that, in order to research and better know architectonic space, it is necessary to understand what he names "existential space", i.e., that concept of space that permits an individual to construct a stable image of what is around him, and, at the same time, makes him belong to a society and a culture.

The need of a space that can be lived, inhabited, or dwelled in underlies an architect's work (even if it is consciously or not) in order for a building to become true architecture. It's this existential experience of space that grants it the sense of place and not of a mere abstraction. As Montaner i Martorell (2002) has stated, "Space has an ideal, theoretical, generic and undefined condition, while place has a concrete, empirical, existential, articulated character, defined down to its details".

The perception, the understanding, and, thus, the appropriation ${ }^{1}$ each person makes of the environment around him is different. However, there is a number of factors (for instance biological, social, cultural, psychological ones, among others) which are common to the vast majority of inhabitants -users, if we wanted to use a colder word-that allow us to assert that, even within this diversity, the built environment will be apprehended, used and dwelled in in a certain way, or, in the worst case, with slight deviations from the way it has been planned to be.

Also, it is well known that, since a few decades ago, architecture practice is carried out having in mind that there are individuals with different types and degrees of disabilities (mainly visual, hearing and motoric impairments), and architects plan and design (whether convinced -this is the most common situation- or just impelled by regulations) spaces so that these can be also inhabited by those people. We speak then about accessibility, but, in fact, this word has come to convey a mostly physical concept: accessibility is, therefore, a way to grant people with disabilities physical access to building or spaces, what, ultimately, allows them to inhabit those spaces.

\footnotetext{
${ }^{1}$ In the very etymological sense of the word: the action of making something one's own
} 
There are, however, many other impairments or disabilities that are not so "visible", and that are, usually, ignored in this task of making the environment accessible. In this sense, Smith (2009) states that, in the design process of buildings (or streets, cities and interiors) almost exclusively two paradigms come into play: that of the client and that of the architect. That is, it is these two agents' vision of reality, of how things -spaces, communications, spatial connections, ...- work and are perceived, what actually shapes the built environment around us. What is more, this is usually accomplished with the assumption that this environment is just a container or a mere scenario in which certain activities or functions are carried out, forgetting the active role it can -and does- play.

On the contrary, for people with particular cognitive or sensory impairments -which are "less visible" as Smith puts it-, among which individuals with autism can be found, this assumption about how spaces will be perceived and dwelled in is far from correct: due to their impairments, they are forced to make an effort, enormous at times, to get to grasp and understand the environment around them. When that struggle takes place, because of their difficulty in processing the information they receive through their senses, a number of elements -music too loud in a supermarket or mall, or just the accumulation of placards, symbols or neon signs, to cite two examples- can become a barrier, somehow jamming the understanding of the environment, and, in turn, originate frustration and strange behaviour (gestures, verbal utterances, weird movements...). Smith points out that, in the eyes of a casual observer being at that precise time in that precise space, the whole situation would be perceived simply as an inappropriate behaviour in a given situation, while, actually, it has been the imbalance between the environment and an individual's ability to adapt to it, to apprehend it, what has triggered the seemingly bad behaviour.

So the surroundings, the built environment, has to be considered an important factor that greatly influences -directly and indirectly- individuals with "less visible" impairments. As architect John Jenkins states, in reference to the design of educational spaces for children with autism -though we consider his affirmation can be applied to individuals of any age and to any type of building-, says:

"Mainstream children are probably more 'able to cope' with badly designed spaces

than an autistic child would be. So the responsibility to create a 'good' environment is brought into sharp relief" (as cited in Scott, 2009, p. 41).

If, in a broad sense, constant reflection on the relationship between the individual and the space around him, between an individual and his (built) environment, is important for the architectural discipline, the particularization of this reflection in the inhabitant with autism can become a significative contribution not only to the architectural field itself -since Architecture, like other Arts and disciplines such as Philosophy, grows when it's rethought-, but also to the understanding of the way people with autism confront spaces and environments, and, what is more important, to the achievement of a greater well-being for them, as well as to the social consideration of their needs and the difficulties they find in their daily life.

\section{Autism}

Although it is probably not necessary for the reader of this chapter to be given a definition or description of autism, we believe it is important here to recall some key concepts and highlight some points that are relevant to the process of designing spaces for people with autism. Also, this will allow us to explicitly declare what we will understand for autism when referring to 
spaces designed for autism or simply designed with individuals with autism in mind ${ }^{2}$. It is well known that the definitions of the autistic disorder, its etiologic accounts, the nosologic considerations, and even, of course, the treatments, have been suffering modifications along time, obviously in tune with progress made on research being done on autism from such different -if complementary- fields as Medicine, Psychology, Psychiatry, Pedagogy or even Philosophy. But, again, it is important to know what characteristics are -or can be- present in individuals with autism so that we can determine what attributes must a built environment have to facilitate its apprehension by them. This will, also, lead to achieve other goals, which lay beyond -but in many ways depend on- the architectural discipline itself, such as aiding the learning process, promoting autonomy, facilitating socialization, ensuring independence or even, from a wider point of view, preserving the dignity of individuals with autism.

\subsection{General concept}

Without any doubt, autism is one of the most fascinating disorders Medicine and Psychology have confronted. In Riviere's words,

"is autistic that person to whom other people become opaque and unpredictable, that person who lives like absent -mentally absent- towards people present, and whose conduct these latter feel incompetent to rule by means of communication". (as cited in Escobar Solano, Caravaca Cantabella, Herrero Navarro \& Verdejo Bolonio, 2008)

This isolation or loneliness is one of the most enigmatic characteristics of autism. In fact, when Austrian-born American psychiatrist Kanner (1943) first describes the autistic disorder, he considers that its pathognomonic sign is the inability to communicate with other people, what leads to an "extreme autistic aloneness". In this very first description, Kanner specifies a number of aspects common to the children he has studied, which we can briefly enumerate as follows:

1. Inability to relate to other people, at least in an ordinary way

2. Extreme autistic aloneness, that seemingly isolates the child from the outer world

3. Apparent resistance to being embraced or lifted

4. Impairments in language, which can include mutism, pronoun reversal, echolalia or idiosyncratic utterances, among others

5. In some cases, an excellent rote memory

6. Preference for certain specific foods, since early age

7. Fear of intense noises

8. Obsessive desire for repetition and insistence on sameness

9. Limited variety of spontaneous activities (like normal play)

10. Strange motoric stereotypies, as spinning or balancing

11. Normal physical appearance

12. Onset during the first three years of life

\footnotetext{
${ }^{2}$ We discuss further on in this chapter the differences between designing buildings and spaces which are specific for people with autism and others that, not being specific, are to be used by them and, thus, must be thought and planned bearing in mind their needs.
} 
Several months later, in 1944, Austrian Hans Asperger, without previous knowledge of Kanner's work, published an article entitled "Autistic psychopathy' in childhood" (see Asperger, 1991), where he studied the cases of several children whose main disorder was the limitation of their social relationships. According to Escobar Solano et al. (2008), and even thought the contrary has been affirmed, the cases described by Asperger correspond to the same symptoms as those depicted by Kanner, although the former covered a wider condition range, from severe neurological damage to children with almost normal development.

\subsection{Brief history of the concept of autism}

Along the years after the appearance of Kanner's and Asperger's article, and due to the spread of psychoanalytical theories, and even though Kanner himself pointed to a probable biological origin, it was considered that a psychodynamic etiology was in the root of the autistic disorder, i.e., that it was elicited by emotional causes. This lead to blame progenitors and to speak about cold mothers or uncaring fathers. Within this line of thought, assertions were made such as that the cause of autism was the desire of the parents that the child did not exist (Bettelheim, 2001). The psychoanalytical therapies that were used aimed at restoring emotional wounds and rebuilding supposedly broken affections. This type of psychodynamic treatment, in many current researchers' opinion, has not contributed too much $^{3}$ (see, for instance, Escobar Solano et al., 2008; Wing, 1968).

From the mid 1960s and until, approximately, the middle of the 1980s, autism started to be considered due to a neurological origin, and thus conceptualized as a cognitive "disarrangement", instead of an affective one (Escobar Solano et al., 2008). Autism began to be researched in a further methodical and rigorous way, so as to try to understand its communication and language alteration, as well as associated social relationship impairments, resistance to change, etc. (for instance, Rutter \& Schopler, 1984; Wing \& Gould, 1979).

Since that stage, and thanks to those advances in research, autism has come to be considered as a development disorder. Hence, it is included among the Pervasive Developmental Disorders (PDDs), which, aside from autistic disorder ${ }^{4}$, comprises others such as Asperger syndrome, Rett syndrome, childhood disintegrative disorder and PPD-not otherwise specified (or PDD-NOS). More recently it has been realized that it is often hard to set clear boundaries among these disorders, but, in fact, there is a continuum within which three main areas are -in some degree- affected. These three are communication -verbal and non-verbal, as impairments are not constrained to heard and spoken language--, social reciprocity and imagination ${ }^{5}$. That is the reason why the expression Autistic Spectrum Disorders (ASD) became the usual name of what we know, generally speaking, as autism. In fact, as it is well known, future fifth edition of Diagnostic and Statistical Manual of Mental Disorders (DSM-5) by American Psychiatric Association (APA), expected by next year (2013), contemplates this naming ${ }^{6}$.

\footnotetext{
${ }^{3}$ Aside from the distress and suffering this kind of assertions may have put on parents, the current literature renders these therapies -advocated, for instance, by Bettelheim (2001) or Tustin (1996)obsolete and superceded by more recent research and praxis.

${ }^{4}$ Which would correspond to Kanner's or classic autism.

${ }^{5}$ The term 'imagination' here must be understood in its widest sense: the ability to mentally view or think of things that are not really present at a given moment -or even that don't exist at all. The impairment in imagination entails, for instance, the lack of symbolic play, imaginative behaviours, and the existence of repetitive interests and activities.

${ }^{6}$ See http://www.dsm5.org/ProposedRevisions/Pages/proposedrevision.aspx?rid=94.
} 


\subsection{Current accounts}

Since Kanner's publication, many theories have tried to account for the behaviour and development observed in people with autism. The aim is not only to find a clear etiology (whether it considers one only cause or combination of different factors, or a range of different causes that lead to the same cerebral injuries, and, therefore, the same symptoms), but also to try to explain the cognitive, emotional or sensory processes carried out by individuals with autism. We will summarize now three of these theories that can be considered to be the most influencing ones in recent times.

\subsubsection{Theory of mind}

Postulated by Baron-Cohen, Leslie \& Frith (1985), this account considers that people with autism lack a "Theory of Mind", i.e., that they are incapable of assigning mental states (emotions, thoughts, etc.) to other people. The well-known Sally-Anne experiment showed that a majority of children with autism failed the test due to their inability to understand that Sally has a particular state of mind (she is unaware of the fact that Anne has moved the marble) which is independent of that of the own child's one. On the contrary, children in the control groups (one of them made of of normal children and a second one comprising children with Down syndrome, with mental ages that were even inferior to those of the autistic group), passed the test with no great difficulty.

This absence of a Theory of Mind (or blindness to other people's mental states) would explain, to a great extent, social impairments observed in people with ASD: social world seems chaotic to them, verbal messages are interpreted in a literal manner, and they do not find it easy to participate in a normal social interaction, since, while it is taking place, it is crucial that each agent or interlocutor be able to understand the fact that the other has a concrete state of mind (he knows something, is thinking about something, feels in a particular way, etc.). It would also account for the usual observation that the child with autism treats people "like objects", since he is not able to recognize a mind in them. It could also mean a lack of self-consciousness (Frith \& Happe, 1999).

\subsubsection{Theory of central coherence}

According to Frith (2006), people with autism would present an impairment of the cerebral mechanism that confers coherence to the wide range of stimuli we receive. Central coherence would allow us, in usual conditions, to assign a meaning to a given stimulus, by means of extracting information from its context. As people with autism would lack this ability to integrate information coming from outside -and even that which is stored, taken from past experiences-, they will not apprehend its meaning or, if they come to grasp it, this meaning will not be readjusted when in new contexts. Consequently, this theory would also explain the ability, at times amazing, that some individuals with autism have to focus on details, whereas they remain unable to integrate the different parts in a meaningful whole ${ }^{7}$. "Weak" central coherence, as Frith names it, would also account for issues as literal understanding of verbal messages -since they are interpreted out of their context-, something that, in turn, occasionally prevents them from discerning irony, metaphorical senses or mere jokes.

\footnotetext{
${ }^{7}$ Bogdashina (2005) talks about gestalt perception, meaning the act of grasping all the details in a single -sensory-image. The term gestalt, then, tries to refer to a holistic perception, but not, as it may seem, to the integration of all the details in a whole.
} 


\subsubsection{Theory of executive functions}

Executive functions are certain mental and cognitive processes such as attention, concentration, planning, etc., used to achieve an objective that has been previously chosen. According to this theory, people with autism lack control -or at least enough control- over these executive functions, an impairment that would limit their ability to carry out things like task switching or focusing their attention on different things -on a given stimulus or on another one, at will-, in order to complete a planned goal. Therefore, this impairment would also be the origin of stereotypied and repetitive behaviours, which would not be correctly governed by an executive or supervisory system (Frith, 2006, p. 31).

\section{Design criteria: literature review}

In this section we will expound -and at times discuss- a number of design criteria, extracted from the scarce existent literature on this matter, that can be applied to the built environment in order to facilitate its apprehension -and appropiation- by people with ASD.

One of the first publications regarding this matter -which should be considered a pioneering work- is that of Richer \& Nicoll (1971). Through a combination of a careful design of a playroom space and its fixtures and some guidelines for the caring staff, the authors aimed to achieve two main goals:

1. Reduction of frustration and arousal.

- By subdividing space in smaller areas, overstimulation and an excessive number of social interactions are avoided. Also, the design provided a retreat box in which the child could calm down.

- Space for activities such as climbing, rolling, sliding, etc. was provided. When children are involved in this kind of games, they are less likely to become overaroused, and this, in turn, facilitates social interactions.

- Stereotypies were not stopped by any means. On the contrary, toys which could easily be played with in repetitive movements were included in the playroom.

2. Reduction of flight behaviours, i.e., all those actions a child with autism carries out to avoid social interactions (moving away, retreating, looking away, etc.), and, simultaneously, facilitation of approaches.

- Structures and fixtures were robust and firmly anchored, so that there was no need to interrupt the children's games with safety warnings or instructions.

- Areas were provided in which the children could demand two types of social interaction: a close tactile contact, and a rough and tumble play.

- In some areas, as in what they called the activity house, physical boundaries somehow force social interaction, but these will be rewarding, since they are framed in a rewarding activity.

It is important to recall that this was not a design-only intervention, but also some guidelines were given to staff about how the playroom was to be used, and what their attitudes should be. The main concern was to avoid approaching the children as much as possible, unless it was the children themselves who were demanding these approaches. Even looking at the children was considered a form of approaching them, unless they seemed motivated enough to begin an interaction. As a result of this intervention on the physical environment, as well as the application of these guidelines, the children with autism developed an increased number of social interactions, and, at the same time, were less involved in their stereotypies. 
Let us highligh some of the design criteria used by Richer \& Nicoll (1971), some of which we find in other authors, too, later in this chapter:

- Subdivision of spaces, cutting off one from another, in a certain way. Mostafa (2008) also carries out a spatial sequence compartmentalization in her intervention in a classroom space.

- Safety and robustness of elements, furniture, or fixtures.

- Minimize intrusion of carers as much as possible, leaving the children free to play, jump, slide, roll, interact, how and when they feel the need to.

- Inclusion of a retreat box.

- Use of elements and materials that are durable (although the authors themselves comment on two failures in their design: the PVC cover of some foam rubber objects turned out to be not bite-proof, and a water fountain was installed incorrectly, what led to floods, and ultimately, had to be removed).

- Controlled sensory stimulation in the different subspaces, ranging from no-stimulus (retreat box) to highly stimulating areas such as the activity house or the so-called stimulus wall.

- Use of light dimmers, to allow staff to create different atmospheres when needed.

Khare \& Mullick $(2008 ; 2009)$ have been carrying out a research by means of which they aim to obtain a series of conclusions that can be applied to so-called Universal Design, particularly in educational spaces. It is important to recall here what this expression refers to: Universal Design (sometimes abbreviated UD) is a paradigm -not exclusively architectural, but indeed applicable to this discipline- which aims at designing objects -buildings, interiors and urban spaces, etc., in our case- in such a way that they can be used by the largest possible number of people, regardless of their particular conditions.

This study by Khare \& Mullick has been divided in six phases, summarized below:

1. Establishing users' needs

2. Laying down environment considerations for autism

3. Definition of design parameters

4. Assessment of the selected design paramenters

5. Preparation of design criteria or recommendations

6. Selection of principles applicable to Universal Design

It is remarkable that this research process and methodology have been designed so that the design suggestions can be assessed later, and, thus, their validity can be verified. Even though the conclusions have not been published yet, we believe it is important to highlight the design parameters -we would better say they are objectives to be accomplished by means of, or with the help of, design- the authors choose -and later assess- as the most beneficial to children with ASD (Khare \& Mullick, 2008):

1. Physical structure: organize environment with clear visual and physical boundaries. These will help to create a definite context for each activity in association with a given space.

2. Maximize visual structure: organize visual environment by means of concrete visual cues. This would comprise aspects as colour coding, numbers, signs, labels, etc. 
3. Provide visual instructions: indicate the sequence of steps to be followed when performing certain activities -in the spaces where these are carried out- by means of not only written guidance, but also images, pictures, visual schedules, etc.

4. Opportunities for community participation: pupils should be involved in everyday social activities.

5. Opportunities for parent participation: involve parents in school activities, thus aiding to address pupils' educational needs.

6. Opportunities for inclusion: provide an environment for children with autism that allows them to interact with their peers.

7. Maximize future independence: create an environment in which the child can learn everyday life skills, as well as vocational ones, that allow them to be independent in the future.

8. Generous spatial standards: these will help children with autism to face social demands, since they are rather wary about their personal space (see note 11 on page10).

9. Provision of withdrawal spaces ${ }^{8}$ : quiet areas in which pupils with autism can retire to avoid or mitigate the stress they can feel in certain moments, when they are in spaces where socially demanding situations may occur.

10. Maximize safety: minimize risks derived from pupils' own conditions, including, in many cases, the misperception of dangers.

11. Maximize comprehension: clear arrangement of spaces, direct routes between them, neat zoning, use of simple forms, and uncluttered interiors help children with autism to perceive -and to apprehend- their school environment.

12. Maximize accessibility ${ }^{9}$ : impairments in movement coordination and balance, epilepsy, restricted attention span, and other difficulties demand that the building be physically accessible.

13. Provide assistance: there should be space enough to help a pupil with autism in doing their learning activities, or in the toilet or the dining room, etc.

14. Maximize durability and minimize maintenance costs: equipment, furnishing, fixtures, fittings, and materials and systems in general should be durable -especially taking into account possible aggressions and misuse by pupils- and require little and inexpensive maintenance.

15. Minimize sensory distractions: environments should not present elements that can become visual, auditive, tactile, etc., distractions -other than the ones specifically and strategically set out for this precise objective -as stated in next point.

16. Facilitate sensory integration ${ }^{10}$ : include multisensory stimuli within the environment, providing opportunities to roll, jump, spin, as well as vibrations, music, visual experiences, etc.

17. Provide flexibility: environment has to be flexible enough to accommodate a wide range of functional skills and different teaching paradigms.

\footnotetext{
${ }^{8}$ Mostafa (2008) talks about haven spaces.

${ }^{9}$ In this case restrictedly understood as easy physical access (see above, page 1)

${ }^{10}$ Davis \& Dubie (2004), for instance, also face sensory integration
} 
18. Allow monitoring for assessment and planning: it is necessary to control or monitor pupils with the lesser degree of distraction and intrusion, in order to assess them, grant their safety and plan activities, teaching strategies, etc.

It could be argued that some of the criteria enumerated above -if not most of them- may not seem specific to pupils with autism. And it would be true to a certain degree, but the fact it is that in that particular case, those parameters become not only adequate -as they would surely be be when talking about individuals without ASD- but essential, and therefore they have to be emphasized and carefully taken into account.

Another interesting contribution Khare \& Mullick (2009) make is the use of evaluation tools to assess the presence of different design criteria in the environment, as well as to measure the performance of children with autism. Their research shows that a high score when evaluating the environment from this point of view was related to a high performance result for children with autism in a given educational setting.

Humphreys (2008) sketches a variety of criteria to be considered when designing buildings for people with ASD. He refers to some clearly architectural concepts that the designer should include in his creations. Thus, he suggests seeking:

- Calm, order and simplicity:

As a example, he mentions a school designed by him and located in Newcastle, United Kingdom, in which younger and older pupils are separated and use each of two units adjacent to a shared piece which holds common services, administration, departments, etc. Each units has a courtyard shaped in an golden spiral which becomes a permanent visual reference along the circulation spaces in the building. Furthermore, the sense of calm and simplicity is not limited to the way in which the plan and sections have been designed, but also applies to the use of materials. At this point Humphreys refers to medieval cistercian cloisters, where the same material is used for every element -pillars, floors, walls, etc.-, and suggests that, doing so, i.e., selecting a limited palette of materials, finishings, textures or colours, the same sense of calm we can find in those places can be achieved.

- Minimal details and materials:

Aside from the above mentioned sense of order, this strategy can minimize the visual distraction excessive detailing brings. Any unnecessary detail should be avoided, altogether with hard edges. Reducing the background visual stimulation to a minimum allows carers and teachers to introduce the precise degree of stimulation according to each child's needs. Also, it is a good idea to consistently define heights of elements such as doors, handles, light switches and others.

- Proportion: With this idea Humphreys brings us back to ancient proportional systems, to Vitruvius, to classical Greek architecture, to the Parthenon's golden proportion, or to the use of Fibonacci series. To sum up, the author suggests trying to confer harmonious proportions on buildings and spaces designed for people with autism.

- Natural light:

Humphreys advocates an extensive use of natural light, but warns against some possible errors: dazzling sun entrance, deep shadows or excessive contrasts, patterned or rhythmic shadow-light sequences, etc., may produce visual overstimulation. Sandblasted -or otherwise similarly treated- glass generates a convenient diffuse and homogeneous illumination out from natural light. Also, the precise design and placing of windows determines the way natural light spreads out in a given space. Skylights, too, or, even better, clerestory windows, can help getting this kind of diffuse lighting. 
- Proxemics $^{11}$ :

Proximity relationships in people with autism may be different to the usual ones. That is the reason we can speak about particular proxemics in individuals with ASD, meaning they may need more space for social relationships, and this has to be taken into account in the design process -including classrooms, corridors, halls, dining-rooms, etc.

- Containment:

This concept refers to the need to monitor children with ASD, but, simultaneously, to the opportunity for them to wander -whenever their schedules and tasks allow them to. To accomplish this goal, the crucial point is to create a safe place where a child with ASD can walk freely. Humphreys exhorts us to look back into history and nature, zen courtyards or natural forms that can provide a convenient degree of containment. He also suggests designing exterior walls that are not obtrusive nor unpleasant.

- Observation:

As noted before, this will fulfil the need of supervision, but avoiding, at the same time, excessive intrusion in the child's activities or interactions.

- Acoustics:

People with ASD often have to make an enormous effort to differentiate sounds, and are more sensitive than other people to noises. The acoustic properties ${ }^{12}$ of materials and constructive elements and systems must be taken into account.

To sum up, the most interesting aspect in Humphrey's work is the use of architectural concepts that convey beneficial outcomes for children with autism. In other words, certain intrinsic characteristics or qualities of a given architectural space can -and will-, if wisely employed, have a positive effect on children -or adults- with ASD.

An magnificient report entitled "Advancing full spectrum housing" (Ahrentzen \& Steele, 2009) must be considered as one of the most in-depth studies on the matter we are discussing up to date. It summarizes previous research which analysed a number of residential settings, including different type of buildings -independent detached and attached houses, clusters of attached homes with common spaces, single-room occupancy units...-, different situations of dwelling -with or without family, with selected friends or agency chosen room-mates-, mixed or exclusionary residential complexes, and different types of care and support situations. The study and, therefore, the report, focuses on adults with ASD and on housing buildings, as the title shows. Several main design goals applicable to residential buildings for people with ASD were worked out, and are enumerated below:

1. Ensure safety and security

2. Maximize familiarity, stability and clarity

3. Minimize sensory overload

4. Allow opportunities to control social interaction and privacy

5. Provide independence and choice opportunities

6. Foster health and wellness

11 Proxemics is the study of the spatial relationships -and, thus, of the amount of space laid- between individuals in different kinds of social and personal situations.

12 Impact, air and flank transmission, reverberation, noise reduction coefficient or acoustic absorption, to name just a few 
7. Improve own dignity

8. Ensure durability

9. Achieve affordability

10. Ensure accessibility and support

To achieve these objectives, the report presents many design criteria or recommendations relative to different aspects of a residential project, as its location, its plan layout, exterior spaces, living and community rooms, kitchens, halls, stairs, ramps, bedrooms, sensory -Snoezelen- rooms, bathrooms, laundry rooms, and also deals with aspects such as technology, visual cues, ventilation, lighting, materials, acoustics, appliances and fixtures. The list of suggestions for each of these sections is comprehensive and detailed. What is more, within each section, each recommendation has been correlated to one of the aforementioned design goals -although some of the suggestions might be considered to be related to more than one of those objectives-. Also, it is to be noted that some of the recommendations provided are not really specific for people with autism, but quality standards that could be employed in any building. However, it is clear that this quality must be more firmly ensured when the inhabitant is an individual with ASD.

Another greatly interesting article is that written by Vogel (2008). Although it specifically focuses on classroom design, the ideas presented can be, as the author herself states, extrapolated to other environments people with ASD have to cope with. In addition, Vogel -without dismissing them- goes beyond considerations about sensory, material or textural issues, or even about spaces layout and conditioning. Again, as was the case of Humphrey's work, some architectural qualities are brought out. According to Vogel, these are, summarized, the qualities a built environment for people with autism must have:

1. Flexible/Adaptable

2. Non-threatening

3. Non-distracting

4. Predictable

5. Controllable

6. Sensory-Motor attuned

7. Safe

8. Non-institutional

In relation to the first characteristics of space enumerated above, it could be argued if this might go against the resistance to change people with autism show. However, in many occasions changes in the use of space are necessary, and a given space may be used in different ways along time -even along a day-. Flexibility, therefore, when correctly understood and wisely introduced in design, would allow use transitions to be made without distorting space, i.e., without abrupt modifications that might alter children with ASD.

Especially relevant are Vogel's thoughts about the need to design spaces which are legible -readable- and 'imageable' -qualities that render them predictable-, since these terms remind us of Kevin Lynch's book "The image of the city" (Lynch, 1998). We will recall now the idea of appropriation and apprehension of the built environment we mentioned in our introduction: the space, the environment, must be read and imagined -i.e., converted to a mental image-, before such a process of appropriation takes place. It is, in fact, the process by means of which 
a space becomes a place, and therefore stops being what French anthropologist Marc Augé names a non-place (Augé, 1993).

British architect Christopher Beaver has published on several occasions (Beaver, 2003; 2006; 2010) about the creation of architectural environments suitable for people with ASD. In particular, he explains certain strategies put into play in the development of a residential-educational centre projected by himself, and suggests them as valid approaches for other type of design projects involving users with autism. These strategies can be summarized as follows:

- Corridors were designed in such a way that they are not any longer mere spaces dedicated to circulate, but can be used, for instance, as playrooms. This, in turn, discharges some other spaces, as the living room, so that they can remain reserved for quieter activities. Also, this approach permits this space's appropriation by the children.

- Ample spaces, to allow the development of the children's activities without excessive proximity.

- Beaver designs two curved walls, that seemingly result in a more pleasant aspect. The building assessment carried out some time after it was put into use (Whitehurst, 2007) -which is one of the few evaluations of this type existent in the literature-states that these curved surfaces are liked by children and that, occasionally, they help them circulate, since children actually walk in contact with them.

- Acoustics are taken into account, avoiding too polished materials, for instance. As Beaver says, sometimes it is difficult to combine this aspect with the need to clean the flooring -soft materials like carpet can be useful to absorb noise, but the downside is that they are harder to clean than shinier ones, whose acoustic behaviour can be problematic.

- Safety is important when designing showers and toilets, and therefore pipes must not remain exposed, and fittings must be firmly fixed -otherwise they could be pulled out of their place. It is also necessary to provide enough common showers and toilets because incontinence is not a rare problem in some children with autism.

- Beaver recommends underfloor heating or radiant ceiling panels, and cross-ventilation, preferably from bottom to top, by means of two windows placed in opposite walls. In common areas he suggests the use of passive ventilation.

- Windows may be a safety problem, and hence Beaver's advice on placing mechanisms to restrict their opening. Also, he suggests that the windows can be locked from the interior. Glazing should be made out of safety glass -both on the exterior and the interior sides-. Another interesting possibility is the opportunity to place blinds inside double glazings.

- Regarding lighting fixtures, Beaver remarks that they have to be resistant even to abuse, but their lines should not imprint on the building and its spaces a sense of institution. They could be even hidden to sight, thus achieving indirect and diffuse illumination. Specifically reminds us to avoid traditional fluorescent lamps, as people with ASD might be greatly sensitive to the flickering produced by them, even though other people will never notice it. A good option which lighting industry offers us is the use of dimmers to control different illumination scenarios, each of which will generate a different ambience.

- It is also important to provide "quiet rooms" where a child having a tantrum -or simply experiencing too much stress, due to sensory overload, for example-can calm. This also helps to prevent the undesirable behaviour to expand to other children, as those conducts sometimes have a 'contagious' quality. Beaver does not seem to treat these spaces as 
"haven" spaces, as Khare \& Mullick (2008; 2009) and Mostafa (2008) do, but they can be also used as such: places where children -or adults- with ASD can retire to and where they may resort to the stereotypies that help them get calmed.

- It is also advisable to provide sensory rooms and gardens, which generate visual, auditive, tactile or olfactory stimuli.

- Colour palette should be adequately chosen, in order to create environments that provide a warm but not overstimulating amtmosphere.

Beaver also points out an important subject: the contrast between the measured, pleasant and protective environment we -hopefully- achieve for the individual with autism and other contexts and spaces in which he will have to manage when away from that precise building, which will not be, probably, so autism-friendly, i.e., will not conveniently accommodate their particular needs and impairments. We will quote his thoughts on this matter, since we believe this reflection is absolutely pertinent:

"But where do we draw the line between environments that prepare the individual for the outside world and the protected environment of the purpose designed building? This is a difficult one for me as I am not a policy maker; I respond to a client's brief. But I do see a dilemma for organisations that seek to provide the ideal autism-friendly building for their children (or adults) who then go out into the world only to find that it is a noisy and confusing place with many dangers for which they are not prepared. The low functioning individual will no doubt find this less of a problem as he/she will more likely be in care for life. It is the individual who lives in both worlds that may have more difficulty. Designers must be aware of this and try to find the right balance for the particular user group that will inhabit his/her building."(Beaver, 2010)

Finally, we will refer to an article written by Ian Scott (2009), who analyses British regulations on inclusive schools in the light of the particular needs of children with ASD. He also reviews Humphreys' work cited above (see page 9 onward). From these two starting points, and out of his professional experience, he extracts several requirements -again mostly focused on educational spaces- which are listed below:

1. To create an ordered and comprehensible spatial structure

2. To generate a mix of small and large spaces

3. Provide the user with more control over environmental conditions

4. To accommodate different teaching strategies for pupils with autism

5. To achieve a balance between safety and independence

6. To reduce and simplify detailing

7. To grant the user active participation in the brief building and design process

8. To appropriately use technology to aid the learning experience of pupils with autism

9. To provide adequate technical specification

However, maybe the most interesting respect in Scott's article is the analysis -based on the requirements he has established beforehand- of four schools: New Struan, in Alloa, Scotland; Netley Primary School ASD Unit, in Camden LA, London; Whitton School ASD Unit, in Twickenham, Richmond LA; and Mossbrook Special Primary School, in Norton, Sheffield. Highly valuable are, too, some comments made by the designers of those buildings, as well as 
by several representatives of the schools, whom the author interviewed ${ }^{13}$. For instance, Jim Taylor, the headteacher at Struan School, in reference to the need of withdrawal spaces that are not excluded from the spatial fabric of the building, says:

"At one point the architects had proposed a withdrawal room or 'snoozelin', where a child could withdraw and calm down if things got too much. We rejected that as we felt that would have been a failing in itself. We wanted the children to have the opportunity to withdraw, but still remain within the social fabric of the school and the building allows for that." (Scott, 2009, p. 38)

Or Sarah Wigglesworth, designer of Mossbrook Special Primary School, who reflects on the necesary balance between the need of boundaries and their sense of confinement:

“Typically it seems a large part of the agenda in relation to designing for autism seems to be about ensuring the children can remain within boundaries with which they are familiar. There are two sides to that in that we understand how the limits of a human environment can provide security and be very comforting, but at worst it could reflect confinement. We wanted to create a balance with something that could be 'outward oriented' and engage the world beyond the classroom, whilst at the same time making the kids feel secure. On a philosophical level you can see architecture as a vessel that gathers the world into it-self and this building certainly does that in lots of ways." (Scott, 2009, p. 49)

Scott's article is, in sum, an outstanding example of the extremely scarce studies of several buildings analysing their adaptation to the concrete needs of people with ASD.

\section{Synopsis of design criteria}

In this section we will outline several responses that architectural design may -by means of project and design mechanisms- give to the needs of people with autism. Whilst it may not be an exhaustive compilation, we will group these strategies according to different impairments that may be aided by them, for the purpose of systematising our discourse.

\subsection{Imagination}

Resistance to changes and a limited ability to imagine are, as has been stated above, two of the most common symptoms present on individuals with ASD. These characteristics lead to difficulties or extreme nervousness when switching tasks or even when walking from a given space to another. The main issue is that they may be unable to imagine, i.e., to elaborate a mental image, what lays behind a door or a wall, even if they know the room they are entering. In their school or home environments this issue is usually faced up to through anticipation of activities that are to be held soon, and avoiding or mitigating, as much as possible, unexpected changes in scheduled tasks and routines.

From the architectural design point of view, the inability to construct a mental image of the environment, as well as to integrate parts in a whole, can be addressed by providing the building with a clear structure, along with elements ${ }^{14}$ that endow it with certain order and unity, in such a way that it becomes easily readable, predictable, imaginable.

\footnotetext{
13 See also one of these comments by John Jenkins, quoted on page 2

${ }^{14}$ For instance, Southerington (2007) uses a handrail that runs along walls in all the spaces of the building she designs, thus providing an element to achieve a degree of visual consistency.
} 
With regard to transitions between spaces, anxiety may be reduced, for instance, with the help of colour coding of doors -showing the use of the spaces behind them- pictograms or even actual pictures that anticipate what we are about to find, or with a decidedly architectural strategy such as creating intermediate transitional threshold spaces where the necessary anticipation can be achieved (see, for instance Scott, 2009, p. 42).

\subsection{Communication}

Impairments in verbal and non-verbal communication, in conjunction with difficulties in information processing, make it essential

"to remove certain psychological 'barriers' and to adapt the environment with cues that [...] are characterized by being concrete and easily perceivable (versus subtle), simple, i.e., comprising few elements (versus complex) and permanent (versus temporary)". (Tamarit et al., 1990)

An individual with ASD usually needs visual support to communication, and often pictograms, pictures of objects and people, among other aids, are used. The built environment should be able to accommodate these forms of communication, planning their right location and integration. As stated above, coding elements with colours, for instance, can also help communication.

It is also of cardinal importance that the visual background be as neutral as possible. An effort must be put on decluttering the environment, removing superfluous elements, minimizing detailing and employing reduced non-vivid chromatic ranges.

\subsection{Social interaction}

Impairments in social interaction are, by definition -although in different degrees-present in individuals with ASD. That is the reason why the different educative strategies aim at aiding in this dimension. Therefore, it will be necessary to provide spaces to allow and even favour those interactions, but bearing in mind that individuals with ASD may present peculiar proxemics (see above, page 10), thus needing ample spaces in which such interchanges can take place. A proper combination of large spaces and small ones -in which one can, at will, interact closer to each other- is advisable.

Furthermore, in some situations an individual with autism may feel overcome by a social demanding situation -he might find himself impelled to participate in different interactions, even in several at the same time- and thus needs a space where to retire in search of greater intimacy, or just a simpler interaction -fewer people, or more familiar ones-.

\subsection{Sensory difficulties}

Difficulties in the reception or processing of sensory stimuli is also a frequent symptom of ASD. These impairments may take the form of visual, auditory, vestibular, olfactory, proprioceptive or tactile hypersensitivity -or hyposensitivity at times-. Multichannel perception -sounds that elicit images or smells, for instance-. Consideration towards this issue will lead us to carefully select colours - not excessively contrasting, saturated or bright-; textures and patterns -again avoiding high contrasts-, acoustic properties of the different materials and constructive elements, lighting -trying to achieve a diffuse, preferably natural, illumination, and remembering to avoid fluorescent tubes, as its flickering and buzzing can alter an individual with auditory or visual hypersensitivity; fixtures; heat, ventilation and air conditioning -reducing gradients of temperature and limiting noises and vibrations-; etc. 
Yet another possible sensory dysfunction is that of pain sensation. For instance, a child -or an adult- with autism may suffer from severe burns if he washes his hands or has a shower with water at high temperature, as he will not pull away. To avoid this type of problems, thermostatic taps can be used, or, at least, the temperature water reaches must be conveniently adjusted. Other elements should also be designed and materials and finishings should be selected in such a way that no one -especially someone insensitive to pain- may not suffer from any accidental injuries.

Aside from these considerations, it is interesting to remember that multisensory stimulation rooms -also called Snoezelen rooms- allow people with autism to 'attune' their sensory perception, -whether mitigating or arising them, in cases of hyposensitivity-, and also to reduce anxiety at given moments.

\subsection{Behaviour and safety}

Behavioural problems are, too, frequent in cases of ASD. Aggressive conduct may arise, and, therefore, elements present in the built environment must be designed and chosen bearing in mind the possibility of eventual abuses. In particular, bathroom equipment, lighting fixtures and mechanisms, hardware, banisters, wall and floor tiles, etc., must be well anchored.

\section{Conclusions}

We have shown that the literature on built environments and their relation to people with ASD and their needs is scarce, in spite of the enormous amount of research on autism that has been carried out in recent years. This interest responds to an important increase in diagnosed cases, due to which prevalence studies show ratios well above the estimations of 1 to 3 cases in 10,000 children that were worked out in last century's early 90s -and even lower before-. It has been stated recently that the proportion reaches one child with autism in 110 births (Center for Disease Control and Prevention, 2009). It is obvious that the rise in prevalence ratios does not correspond to a real increment in the number of cases -at least not exclusively-, but also to the expansion of the very concept of autism and its diagnostic criteria, and to improvements in educational and health services that permits for an earlier diagnosis, altogether with a higher degree of awareness on autism (Ahrentzen \& Steele, 2009). In spite of that, those ratios bring up the fact that people with autism constitute a wide population group, that require attention and services from society. The disciplinary field of Architecture should move in this direction, too. Within a few decades architects and urban planners have become aware of the need to design without the so-called 'architectural barriers' which limit access and mobility for people with - physical- disabilities. However, within this concept of barrier there has been no place for those elements that limit the use of our environment for individuals with cognitive or mental disabilities. We, thus, need to learn that, as Baumers \& Heylighen $(2009 ; 2010)$ state, these people perceive space in a unique, different style: with the "eyes of the mind".

It is mandatory to advance in research on this matter, with further analyses and assessments of architectural realisations that have been designed and built for people with autism, and of the adaptation to these users' needs. Innovative and imaginative design solutions should be pointed out by this research, as well as failures and errors.

In spite of the fact that it is difficult -i.e., costly- to produce interventions in the built environment, even when scales are small, examples as Magda Mostafa's work (2008) show that they are possible and that, when systematically carried out and assessed, they can provide 
us with useful information about how, and to what extent, these realisations improve the experience people with ASD have in their environment.

We will finish this chapter quoting Spanish architect Luis Fernández-Galiano. His words may help other architects and designers -actually, any agent involved in designing and planning buildings- to grasp what their role should be, and especially what challenges are to be faced when shaping environments for people with autism:

"Dwelling is a difficult job. As the trade of living, that of dwelling requires continuous learning and attention, demands a meticulous and systematic effort, and involves an inordinate investment of time and energy. It is therefore surprising to verify the naturalness with which the majority of us get to execute the complicated rituals of habitable space. As happens with languaje, expertise is achieved with habit, that rules and domesticates gestures and voices through everyday reiteration of movements and words. Well, this exhausting and habitual trade has in the architect an obstacle or an ally" (as cited in Oyarzun, 2005).

\section{References}

Ahrentzen, S. \& Steele, K. (2009). Advancing full spectrum housing, Technical report, Arizona Board of Regents, Phoenix, USA.

Asperger, H. (1991). Autistic psychopathy in childhood, in U. Frith (ed.), Autism and Asperger syndrome, Cambridge University Press, Cambridge, p. 37.

Augé, M. (1993). Los no lugares, espacios del anonimato : antropología sobre modernidad, Gedisa, Barcelona.

Baron-Cohen, S., Leslie, A. \& Frith, U. (1985). Does the autistic child have a "theory of mind"?, Cognition 21(1): 37-46.

Baumers, S. \& Heylighen, A. (2009). The eyes of the mind. architecture and mental disability, Engaging Artifacts, Oslo.

Baumers, S. \& Heylighen, A. (2010). Harnessing different dimensions of space: The built environment in auti-biographies, in P. Langdon, P. J. Clarkson \& P. Robinson (eds), Designing Inclusive Interactions: Inclusive Interactions Between People and Products in Their Contexts of Use, Springer-Verlag, London, UK, pp. 13-23.

Beaver, C. (2003). Breaking the mould, Communication 37(3): 40.

Beaver, C. (2006). Designing environments for children and adults with ASD, Cape Town.

Beaver, C. (2010). Autism-friendly environments, The autism file (34): 82-85.

Bettelheim, B. (2001). La fortaleza vacía: Autismo infantil y el nacimiento del yo, number 29 in Saberes Cotidianos, Paidós, Barcelona.

Bogdashina, O. (2005). Communication issues in autism and Asperger syndrome: do we speak the same language?, Jessica Kingsley Publishers.

Center for Disease Control and Prevention (2009). Prevalence of Autism Spectrum Disorders. Autism and Developmental Disabilities Monitoring Network, United States, 2006, MMWR 58(SS-10): 1-20.

Davis, K. \& Dubie, M. (2004). Sensory integration: Tips to consider, The Reporter 9(3): 3-8.

Escobar Solano, M., Caravaca Cantabella, M., Herrero Navarro, J. \& Verdejo Bolonio, M. (2008). Necesidades educativas especiales del alumnado con trastornos del espectro autista., Atención a la diversidad: materiales para la formación del profesorado, Consejería de Educación, Formación y Empleo de la Región de Murcia. Centro de Profesores y Recursos de Cieza, Murcia.

Frith, U. (2006). Autismo: hacia una explicación del enigma, Alianza Editorial, Madrid. 
Frith, U. \& Happe, F. (1999). Theory of mind and Self-Consciousness: what is it like to be autistic?, Mind and Language 14(1): 82-89.

Heidegger, M. (2001). Conferencias y artículos, Ediciones del Serbal, Barcelona.

Humphreys, S. (2008). Architecture and autism.

URL: http://www.auctores.be/auctores_bestanden/UDDA\%2003102008\%20S\%20Humph reys.pdf

Kanner, L. (1943). Autistic disturbances of affective contact, Nervous child 2(2): 217-230.

Khare, R. \& Mullick, A. (2008). Educational spaces for children with autism: design development process, CIB W 084 Proceedings, Building Comfortable and Liveable Environment for All, Atlanta, USA, pp. 66-75.

Khare, R. \& Mullick, A. (2009). Incorporating the behavioral dimension in designing inclusive learning environment for autism, International Journal of Architectural Research 3(3): 45-64.

Lynch, K. (1998). La imagen de la ciudad, Gustavo Gili, Barcelona.

Montaner i Martorell, J. (2002). La modernidad superada : arquitectura, arte y pensamiento del siglo XX, Gustavo Gili, Barcelona.

Mostafa, M. (2008). An an architecture for autism: Concepts of design intervention for the autistic user, International Journal of Architectural Research 2(1): 189-211.

Oyarzun, D. (2005). Arquitectura y discapacidad. Centro de atención integral para niños autistas., Proyecto de título, Universidad de Chile, Santiago de Chile.

Richer, J. M. \& Nicoll, S. (1971). A playroom for autistic children, and its companion therapy project, British Journal of Mental Subnormality 17(33): 132-143.

Rutter, M. \& Schopler, E. (eds) (1984). Autismo. Reevaluación de los conceptos y el tratamiento, Alhambra Universidad, Alhambra, Madrid.

Scott, I. (2009). Designing learning spaces for children on the autism spectrum, Good Autism Practice 10(1): 36-51.

Smith, D. (2009). Spatial design as a facilitator for people with less visible impairments, Australasian Medical Journal 1(13): 220-227.

Southerington, E. A. (2007). Specialized Environments: Perceptual Experience as Generator of Form, Master project, Cincinnati, USA.

Tamarit, J., de Dios, J., Domínguez, S. \& Escribano, L. (1990). Proyecto de estructuración ambiental en el aula de niños autistas, Technical report, Consejería de Educación de la Comunidad Autónoma de Madrid y Dirección General de Renovación Pedagógica del Ministerio de Educación y Ciencia, Madrid.

Tustin, F. (1996). Estados autísticos en los niños, number 109 in Psicología Psiquiatría Psicoterapia, Paidós, Barcelona.

Vogel, C. L. (2008). Classroom design for living and learning with autism, Autism Asperger's Digest.

Whitehurst, T. (2007). Evaluation of features specific to an ASD designed living accommodation, Technical report, Sunfield Research Institute.

Wing, J. (1968). Review of Bettelheim: "The empty fortress", British Journal of Psychiatry 114: 788-791.

Wing, L. \& Gould, J. (1979). Severe impairments of social interaction and associated abnormalities in children: epidemiology and classification, Journal of autism and developmental disorders 9(1): 11-29. 


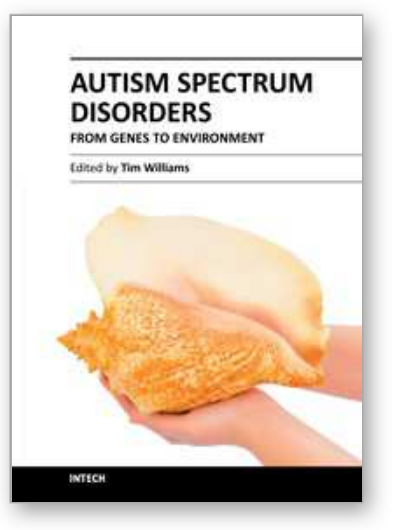

\author{
Autism Spectrum Disorders - From Genes to Environment \\ Edited by Prof. Tim Williams
}

ISBN 978-953-307-558-7

Hard cover, 400 pages

Publisher InTech

Published online 06, September, 2011

Published in print edition September, 2011

Autism spectrum disorders are a major topic for research. The causes are now thought to be largely genetic although the genes involved are only slowly being traced. The effects of ASD are often devastating and families and schools have to adapt to provide the best for people with ASD to attain their potential. This book describes some of the interventions and modifications that can benefit people with ASD.

\title{
How to reference
}

In order to correctly reference this scholarly work, feel free to copy and paste the following:

Pilar Arnaiz Sánchez, Francisco Segado Vázquez and Laureano Albaladejo Serrano (2011). Autism and the Built Environment, Autism Spectrum Disorders - From Genes to Environment, Prof. Tim Williams (Ed.), ISBN: 978-953-307-558-7, InTech, Available from: http://www.intechopen.com/books/autism-spectrum-disordersfrom-genes-to-environment/autism-and-the-built-environment

\section{INTECH}

open science | open minds

\author{
InTech Europe \\ University Campus STeP Ri \\ Slavka Krautzeka 83/A \\ 51000 Rijeka, Croatia \\ Phone: +385 (51) 770447 \\ Fax: +385 (51) 686166 \\ www.intechopen.com
}

\author{
InTech China \\ Unit 405, Office Block, Hotel Equatorial Shanghai \\ No.65, Yan An Road (West), Shanghai, 200040, China \\ 中国上海市延安西路65号上海国际贵都大饭店办公楼 405 单元 \\ Phone: +86-21-62489820 \\ Fax: +86-21-62489821
}


(C) 2011 The Author(s). Licensee IntechOpen. This chapter is distributed under the terms of the Creative Commons Attribution-NonCommercialShareAlike-3.0 License, which permits use, distribution and reproduction for non-commercial purposes, provided the original is properly cited and derivative works building on this content are distributed under the same license. 